\title{
Association between polyclonal B cell activation and the presence of autoantibodies in mice infected with Yersinia enterocolitica $0: 3$
}

\author{
B.M.M. Medeiros ${ }^{1}$, \\ A.M. Costa ${ }^{1,2}$, \\ P.M.F. Araújo ${ }^{2}$ \\ and D.P. Falcão ${ }^{1}$
}

\author{
1Departamento de Ciências Biológicas, Faculdade de Ciências Farmacêuticas, \\ Universidade Estadual Paulista, 14801-902 Araraquara, SP, Brasil \\ ${ }^{2}$ Departamento de Microbiologia e Imunologia, Instituto de Biologia, \\ Universidade Estadual de Campinas, 13083-970 Campinas, SP, Brasil
}

\section{Correspondence}

B.M.M. Medeiros

Departamento de Ciências Biológicas Faculdade de Ciências Farmacêuticas Universidade Estadual Paulista Rodovia Araraquara-Jaú, Km 1 14801-902 Araraquara, SP

Brasi

Fax: 55 (016) 222-0073

Presented at the 6th International Symposium on Yersinia, Rome, Italy, September 26-28, 1994.

Research partially supported by FAPESP (No. 89/3435-7).

\section{Abstract}

Eight-week old conventional female Swiss mice were inoculated intravenously with Yersinia enterocolitica O:3. A second group of normal mice was used as control. Five mice from each group were bled by heart puncture and their spleens were removed for spleen cell collection on the 3rd, 5th, 7th, 10th, 14th and 21st day after infection. Immunoglobulin-secreting spleen cells were detected by the isotypespecific protein A plaque assay. Total immunoglobulin levels were determined in mouse serum by single radial immunodiffusion and the presence of autoantibodies was determined by ELISA. We observed a marked increase in the total number of cells secreting immunoglobulins of all isotypes as early as on the 3rd day post-infection and the peak of secretion occurred on the 7th day. At the peak of the immunoglobulin response, the total number of secreting cells was 19 times higher than that of control mice and most immunoglobulin-secreting cells were of the $\operatorname{IgG}_{2 \mathrm{a}}$ isotype. On the 10th day post-infection, total serum immunoglobulin values were 2 times higher in infected animals when compared to the control group, and continued at this level up to the 21st day post-infection. Serum absorption with viable $Y$. enterocolitica cells had little effect on antibody levels detected by single radial immunodiffusion. Analysis of serum autoantibody levels revealed that $Y$. enterocolitica infection induced an increase of antimyosin and anti-myelin immunoglobulins. The sera did not react with collagen. The present study demonstrates that $Y$. enterocolitica $\mathrm{O}: 3$ infection induces polyclonal activation of murine $\mathrm{B}$ cells which is correlated with the activation of some autoreactive lymphocyte clones.
Key words - Yersinia enterocolitica - Polyclonal activation - Experimental infection - Autoantibodies 


\section{Introduction}

Intestinal infections with Yersinia enterocolitica in humans can be followed by sequelae that include reactive arthritis and other autoimmune diseases (1). The development of arthritis is mostly determined by genetic susceptibility. Approximately $90 \%$ of these patients present the HLA-B27 antigen (2).

The pathogenesis of reactive arthritis continues to be obscure. The expression of the disease is probably multifactorial (3). Strucfollowed by the development of autoantithese autoantibodies may result from polyclonal B lymphocyte activation. Resting B

Figure 1 - Number of plaqueforming cells (PFC) of total Ig present in the spleen of control mice and mice infected with 1.2 $\times 10^{8}$ cells $/ \mathrm{ml}$ of $Y$. enterocolitica $0: 3$. Results are reported as the average values of plaque-forming cells/spleen for 5 mice in each group. The standard deviation was always less than $25 \%$ of the observed values. tures of the bacterial cell envelope becoming similar to, or possibly modifying HLA-B27 antigens with a subsequent autoimmune response may contribute to the triggering of injury to host cells.

Clinical $Y$. enterocolitica infections are bodies including antibodies against smooth muscle, connective tissue, renal tubular epithelium, and the basement membrane of thyroid epithelial cells (4-6). The production of cells with receptors directed against autologous structures may be stimulated as a result of the microorganism-host relationship.

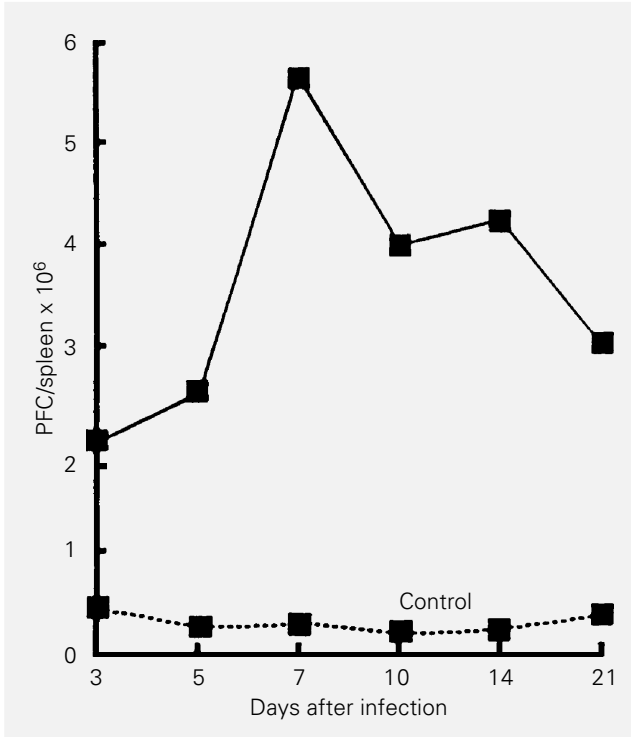

Yersinia enterocolitica biotype 4, serotype O:3, phagotype VIII isolated from human diarrheic feces was studied. This strain harbored the 40-48-MDa virulence plasmid and was positive to virulence tests related to plasmid-mediated gene expression (temperature-dependent autoagglutination, calciumdependent growth at $37^{\circ} \mathrm{C}$ and Congo red absorption on CR-MOX agar), and negative to virulence tests related to chromosomal gene expression (pyrazinamidase production, salicin fermentation and esculin hydrolysis).

\section{Experimental infection of mice}

Thirty eight-week old conventional female Swiss mice were inoculated intravenously with a $0.5-\mathrm{ml}$ suspension of $Y$. enterocolitica $\mathrm{O}: 3\left(1.2 \times 10^{8}\right.$ cells $\left./ \mathrm{ml}\right)$. A second group of 30 normal mice was used as control. Five mice from each group were bled by heart puncture and their spleens were removed for spleen cell collection on the 3rd, 5 th, 7th, 10th, 14th and 21 st day after infection. Sera were separated and stored at $-20^{\circ} \mathrm{C}$. Spleen cells were utilized immediately in the protein A plaque assay. Cell viability was assessed by Trypan blue exclusion.

\section{Isotype-specific protein A plaque assay}

Immunoglobulin-secreting spleen cells were detected by the protein A plaque assay (7). Rabbit anti-mouse Ig was prepared in our laboratory. Rabbit anti-mouse IgM, IgG , $_{1}$ 
$\operatorname{IgG}_{2 \mathrm{a}}, \operatorname{IgG}_{2 \mathrm{~b}}, \operatorname{IgG}_{3}$ and $\mathrm{IgA}$ were purchased from SEROTEC (Oxford, England). Each assay was done in duplicate.

\section{Quantitation of total immunoglobulin levels}

Total immunoglobulin levels were determined in mouse serum by single radial immunodiffusion according to the method of Mancini et al. (8). Serum absorption with viable bacteria was performed by the method of Ewing (9).

\section{Autoantigens}

The autoantigens used in the present study, myosin, myelin and collagen type I, were prepared at the Department of Microbiology and Immunology, UNICAMP, Campinas, SP. Myosin was isolated from rabbit muscle and prepared according to Offer et al. (10), myelin was isolated from mouse brain according to Diebler et al. (11), and collagen type I from mouse tail tendon according to Miller and Rhodes (12).

\section{Enzyme-immunoassay (ELISA) (13)}

Polystyrene microtiter plates were sensitized with $100 \mu$ lof the autoantigens (myosin, myelin and collagen type I) diluted with $0.06 \mathrm{M}$ sodium carbonate-bicarbonate buffer, $\mathrm{pH} 9.6$, to a concentration of $20 \mu \mathrm{g} / \mathrm{ml}$. The plates were then incubated for $18 \mathrm{~h}$ at $4^{\circ} \mathrm{C}$ and washed three times with phosphate-buffered physiological saline containing $0.05 \%$ Tween 20 (PBS/T). After washing, $100 \mu$ l of a serum sample diluted $1 / 100$ in PBS/T containing $1 \%$ bovine serum albumin (PBS/T/ BSA) was added and incubated for $2 \mathrm{~h}$ at $37^{\circ} \mathrm{C}$. The plates were washed and $100 \mu \mathrm{l}$ of peroxidase-conjugated rabbit anti-mouse immunoglobulin diluted 1/1000 in PBS/T/BSA was added. After $1 \mathrm{~h}$ of incubation at $37^{\circ} \mathrm{C}$ followed by an additional wash, $100 \mu \mathrm{l}$ of 1 $\mathrm{mg} / \mathrm{ml}$ o-phenylene diamine in $0.1 \mathrm{M}$ citrate phosphate buffer, $\mathrm{pH}$ 5.0, containing $0.03 \%$

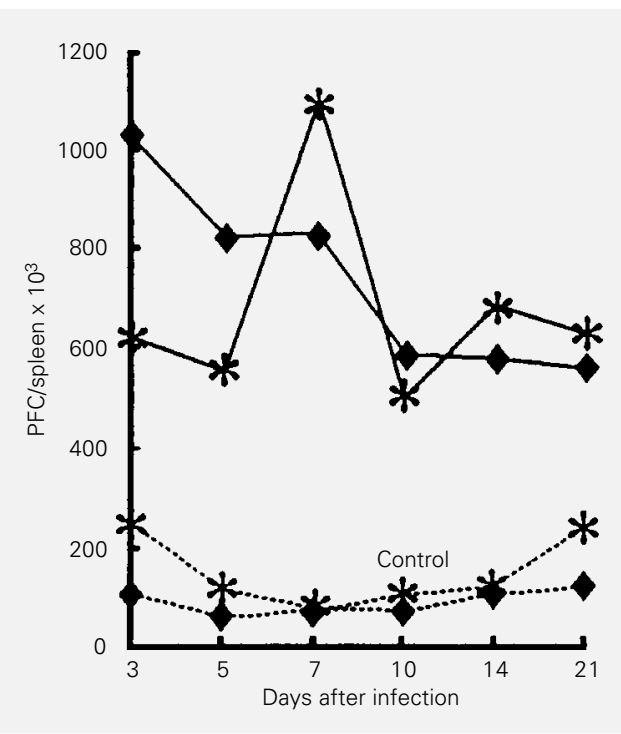

Figure 2 - Number of plaqueforming cells (PFC) of $\operatorname{lgM}(\bullet)$ and $\lg A(*)$ isotypes in the spleen of control mice and mice infected with $1.2 \times 10^{8}$ cells $/ \mathrm{ml}$ of $Y$. enterocolitica O:3. Results are reported as the average values of plaque-forming cells/ spleen for 5 mice in each group. The standard deviation was always less than $25 \%$ of the observed values. hydrogen peroxide was added and the plates were incubated at $35^{\circ} \mathrm{C}$ for $10 \mathrm{~min}$. Finally, the reaction was stopped with $100 \mu \mathrm{l} 3 \mathrm{~N}$ hydrochloric acid. Absorbance was read with a spectrophotometer (UNISKAN-II, FLOW) at $492 \mathrm{~nm}$. All serum samples were assayed in duplicate and the results are reported as the average value.

\section{Results}

The determination of the kinetics of immunoglobulin-secreting spleen cells in the mice infected with Yersinia enterocolitica O:3 showed a marked increase in the total number of cells secreting immunoglobulins as early as on the 3rd day post-infection and the peak of secretion occurred on the 7th day (Figure 1). At the peak of the immunoglobulin response, the total number of secreting cells was 19 times higher than that of control mice. IgM peaked on the $3 \mathrm{rd}$ day and IgA on the 7 th day (Figure 2). The cells secreting the IgG subclasses peaked on the 7th day postinfection and most Ig-secreting cells produced the $\mathrm{IgG}_{2 \mathrm{a}}$ isotype (Figure 3 ).

The determination of total immunoglobulins in the serum of infected animals revealed that on the 10th day post-infection total serum immunoglobulin values were 2 
Figure 3 - Number of plaqueforming cells (PFC) of the IgG subclasses $\lg _{1}(\boldsymbol{\nabla}), \lg _{2}$ a, $(8), \lg _{2 b}(\bullet)$ and $\operatorname{lgG}_{3}(\mathbf{\Lambda})$ in the spleen of control mice and mice infected with $1.2 \times 10^{8} \mathrm{cells} / \mathrm{ml}$ of $Y$. enterocolitica O:3. Results are reported as the average values of plaque-forming cells/ spleen for 5 mice in each group. The standard deviation was always less than $25 \%$ of the observed values.
Figure 4 - Kinetics of development of autoantibodies in the sera of mice infected with $Y$. enterocolitica $\mathrm{O}: 3$, detected by ELISA. The sera were diluted $1 /$ 100. The antigens utilized in the sensitization of the plates were myosin $(20 \mu \mathrm{g} / \mathrm{ml})(*)$, myelin $(20$ $\mu \mathrm{g} / \mathrm{ml})(\bullet)$ and collagen type I $(20 \mu \mathrm{g} / \mathrm{ml})(\boldsymbol{\square})$. The sera of the control mice were also tested and the average values obtained with the different autoantigens are presented along the dotted line with the origin on the ordinate. The standard deviation was always less than $10 \%$ of the observed values.
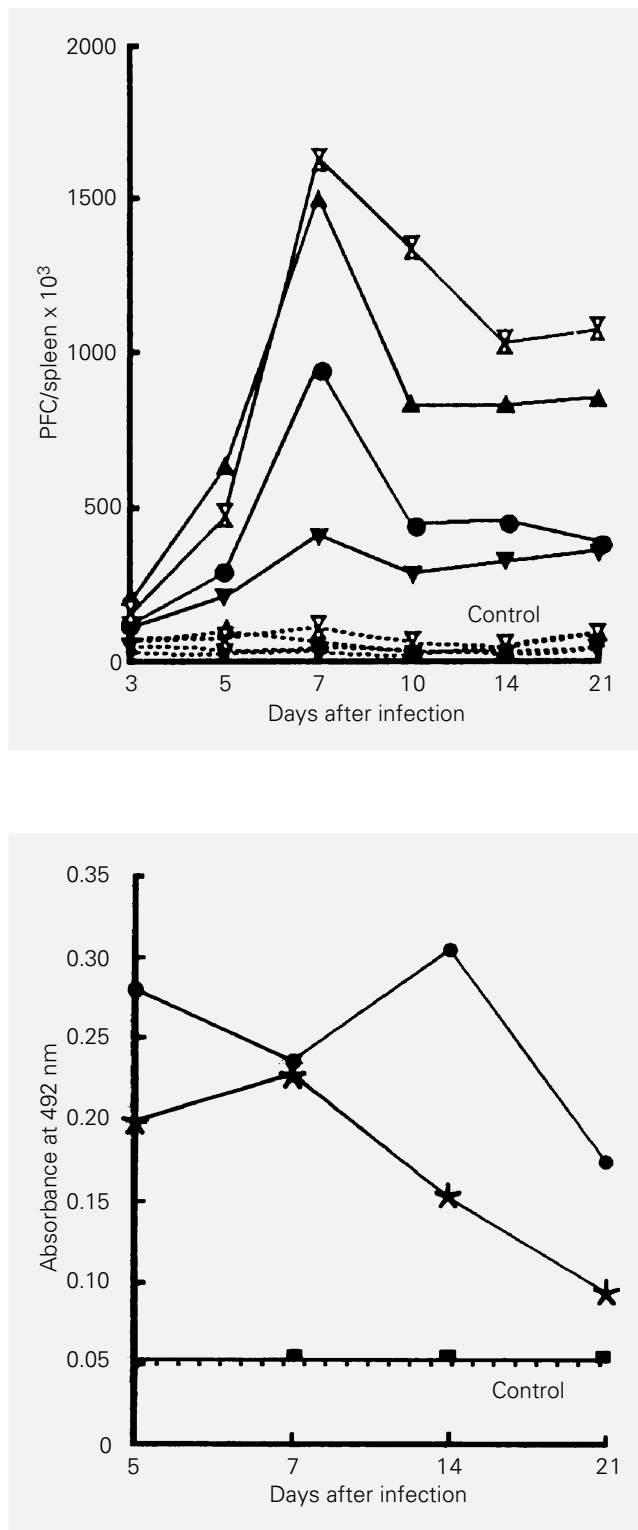

times higher in infected animals when compared to the control group, and remained at that level up to the 21st day post-infection. When these sera were absorbed with viable $Y$. enterocolitica $\mathrm{O}: 3$ cells to remove specific antibodies, we noted that the antibody levels detected by single radial immunodiffusion were $10 \%$ lower when compared to the serum not absorbed.

The analysis of autoantibodies revealed that the sera of infected animals reacted with myosin and myelin on the 5th, 7th and 14th day post-infection and the reactivity to my- elin was more intense than to myosin. The sera did not react with collagen (Figure 4).

\section{Discussion}

The mechanisms by which arthritogenic pathogens interact with the human immune system to produce inflammatory arthritic diseases are not fully understood. These pathogens have the capacity to selectively modulate the immune response of the infected human host and polyclonal lymphocyte stimulation is one of the immunomodulatory mechanisms used by them (14).

In a recent work, Lundgren et al. (15) demonstrated that the outer membrane protein, invasin, of $Y$. pseudotuberculosis is a polyclonal activator of human peripheral $\mathrm{B}$ cells.

The results obtained in the present study indicate the occurrence of polyclonal activation of B lymphocytes in animals infected with $Y$. enterocolitica $\mathrm{O}: 3$. This activation is not limited to certain isotypes since the number of secretory cells of all isotypes was increased, but the majority of immunoglobulin-secreting cells produced the $\mathrm{IgG}_{2 \mathrm{a}}$ isotype

The absorption of sera of infected mice with viable $Y$. enterocolitica $0: 3$ cells to remove specific antibodies had little effect on antibody levels detected by single radial immunodiffusion, indicating that infection with the bacterium provoked polyclonal activation of the repertoire of B lymphocytes and not simply of the clones involved in the production of specific anti-Yersinia antibodies.

Polyclonal lymphocyte activation induced by bacterial endotoxins and superantigens may contribute to the development of autoimmunity. Bacterial infections may lead to the stimulation of many lymphocytes some of which are autoreactive clones normally anergic to stimulation with autoantigens (16).

Recently, Stuart and Woodward (17) demonstrated that $Y$. enterocolitica serotype 0:8 (WA) produces one or more molecules with 
properties consistent with those of $\mathrm{T}$ cell superantigens. These molecules induce expansion and activation of host $\mathrm{T}$ cells and this activation may lead to the expansion of clones of normally suppressed autoreactive $\mathrm{T}$ cells and/or favor the production of antibodies by B cells.

Luo et al. (18) reported that immunization of mice with $Y$. enterocolitica $\mathrm{O}: 8$ (WA) provoked the development of autoantibodies directed against the thyroid-stimulating hormone receptor (TSHr) and may generate the initial stimulus necessary for the rupture of autotolerance to TSHr, eventually leading to the development of autoimmunity to TSHr.

Although the panel of autoantigens that we used was limited, the present study demonstrates that $Y$. enterocolitica $\mathrm{O}: 3$ infection induces polyclonal activation of murine $\mathrm{B}$ cells which is correlated with the activation of some autoreactive lymphocyte clones, with the production of autoantibodies for myelin and myosin.

\section{Acknowledgment}

The authors are grateful to V.A.A. Mallavolta for technical support.

\section{References}

1. Larsen JH (1979). The spectrum of clinical manifestations with Yersinia enterocolitica and their pathogenesis. Contributions to Microbiology and Immunology, 5 : 257-269.

2. Laitinen O, Leirisalo M \& Skylv G (1977). Relation between HLA-B27 and clinical features in patients with Yersinia arthritis. Arthritis and Rheumatism, 20: 1121-1124.

3. Van Bohemen CHG, Nabbe AJJM, Grumet FC, Landheer JE, Dinant HJ \& Zanen HC (1986). Lack of correlation between HLA-B27 like antigenic epitopes on Shigella flexneri and occurrence of reactive arthritis. Clinical and Experimental Immunology, 65: 679-682.

4. Gripenberg $M$, Miettinen A, Kurki $P$ \& Linder E (1978). Humoral immune stimulation and antiepithelial antibodies in Yersinia infection. Arthritis and Rheumatism, 21: 904-908.

5. Montplaisir S, Gagné $M$, Dubois $R$, Gengoux P \& Pelletier M (1979). Brush border membrane antibodies in Yersinia infection and other diseases. Contributions to Microbiology and Immunology, 5: 351-358.

6. Shenkman L \& Bottone EJ (1981). The occurrence of antibodies to Yersinia enterocolitica in thyroid diseases. In: Bottone EJ (Editor), Yersinia enterocolitica. CRC Press, Boca Raton, 135-144.
7. Bernabé RR, Tuneskog M, Forni L, Martinez AC, Holmberg D, Ivars F \& Coutinho A (1981). The protein A plaque assay for the detection of immunoglobulin-secreting cells. In: Bernabé RR, Tuneskog M, Forni L, Martinez AC \& Coutinho A (Editors), Immunological Methods. Vol. II. Academic Press, New York, 187-197.

8. Mancini G, Carbonara A \& Heremans J (1965). Immunochemical quantitation of antigens by single radial immunodiffusion. Immunochemistry, 2: 235-254.

9. Ewing WH (1986). Edwards and Ewing's Identification of Enterobacteriaceae. 4th edn. Elsevier Science Publishing, New York.

10. Offer G, Moos G \& Starr R (1973). A new protein of the thick filaments of vertebrate skeletal myofibrils. Journal of Molecular Biology, 74: 653-657.

11. Diebler G, Martenson R \& Kies M (1972). Large scale preparation of myelin basic protein from central nervous tissue of several mammalian species. Preparative Biochemistry, 2: 139-165.

12. Miller EJ \& Rhodes RK (1982). Preparation and characterization of different types of collagen. Methods in Enzymology, 82: 33-64.
13. Araujo PMF, Holmberg D, Martinez AC \& Coutinho A (1987). Idiotypic multireactivity of "natural antibodies": "natural" antiidiotypes also inhibit helper cells with cross-reactive clonotypes. Scandinavian Journal of Immunology, 25: 497-506.

14. Lahesmaa $R$, Shanafelt M-C, Steinman L \& Peltz G (1994). Immunopathogenesis of human inflammatory arthritis: lessons from Lyme and reactive arthritis. Journal of Infectious Diseases, 170: 978-985.

15. Lundgren E, Carballeira N, Vazquez R, Dubinina $E$, Brändén $H$, Persson $H$ \& WolfWatz H (1966). Invasin of Yersinia pseudotuberculosis activates human peripheral B cells. Infection and Immunity, 64: 829-835.

16. Marrack P \& Kappler JW (1993). How the immune system recognizes the body. Scientific American, 269: 49-55.

17. Stuart PM \& Woodward JG (1992). Yersinia enterocolitica produces superantigenic activity. Journal of Immunology, 148: 225-233.

18. Luo G, Fan JL, Seetharamaiah GS, Desai RK, Dallas JS, Wagle N, Doan R, Niesel DW, Klimple GR \& Prabhakar BS (1993). Immunization of mice with Yersinia enterocolitica leads to the induction of antithyrotropin receptor antibodies. Journal of Immunology, 151: 922-928. 